\title{
MODEL PEMBERDAYAAN SUKU ANAK DALAM BIDANG KESEHATAN DI KECAMATAN BATIN XXIV KABUPATEN BATANGHARI
}

\author{
Empowerment Model Of Indigenous Community in Health Sector on Batin XXIV Sub-District \\ Batanghari District
}

\author{
M. Ridwan ${ }^{1}$, Oka Lesmana ${ }^{1}$ \\ ${ }^{1}$ Program Studi Ilmu Kesehatan Masyarakat, Fakultas Kesehatan Masyarakat Universitas Jambi.
}

\begin{abstract}
Abstrak
Permasalahan kesehatan suku anak dalam sangat kompleks terutama perilaku hidup bersih dan sehat (kondisi jamban, gizi, kebersihan diri, cuci tangan pakai sabun serta kondisi lingkungan pemukiman serta beberapa penyakit (kekurangan gizi, muntaber, malaria dan penyakit kulit). Tujuan penelitian ini untuk mengembangkan suatu model pemberdayaan yang tepat pada suku anak dalam (SAD). Penelitian kualitatif dengan rancangan studi kasus. Pengambilan sampel dilakukan dengan pendekatan purposive sampling sebanyak 27 orang (10 orang masyarakat $\mathrm{SAD}, 1$ Orang petugas puskesmas, 1 orang petugas dinas kesehatan dan 4 orang tumenggung/ketua adat). Pengumpulan data melalui wawancara mendalam dan FGD. Analisis data menggunakan pendekatan content analysis. Kondisi geografis. kebiasaan berpindah pemukiman pasca kedukaan dan kebiasaan menyebar serta akses jalan yang kurang baik merupakan hambatan petugas dalam memberikan pelayanan kesehatan. Temuan dalam penelitian ini bahwa adat larangan seorang perempuan SAD bertemu dengan seorang lelaki diluar rumah menjadi permasalahan bagi petugas kesehatan. "SAD Care" merupakan bentuk pelayanan berbasis mobil terpadu yang menggabungkan upaya promotif dan preventif (posyandu dan posbindu), kuratif dan pengobatan tradisional oleh masyarakat SAD berbasis gender. Penggabungkan empat upaya pelayanan kesehatan berbasis mobil terpadu merupakan model pemberdayaan masyarakat SAD. Pemerintah Daerah agar mengalokasikan anggaran dengan menyediakan mobil bus sebagai pelayanan Kesehatan Tingkat Pertama (FKTP) yang dapat memudahkan masyarakat jika harus dirujuk menggunakan kartu BPJS.
\end{abstract}

Kata Kunci : Pemberdayaan, SAD Care, Suku Anak Dalam

\begin{abstract}
Suku Anak Dalam (SAD) health problems are very complex, especially clean and healthy behaviors (latrine conditions, nutrition, personal hygiene, hand washing and residential environment conditions and some diseases (malnutrition, vomiting, malaria and skin diseases). The purpose of this research is to develop an empowerment model that right on Suku Anak Dalam (SAD) Qualitative research with case study design Sampling was carried out with a purposive sampling approach of 27 people (10 SAD community members, 1 puskesmas officer, 1 health officer and 4 tumenggung / adat leaders). data through in-depth interviews and FGDs. Data analysis using content analysis approach. Geographical conditions, the habit of moving settlements after grief and poor road access are obstacles for officers to provide health services. The findings in this study that the traditional prohibition of a SAD woman meeting a man outside the home was a problem for health workers. "SAD Care" is a form of integrated car-based service that combines promotive and preventive efforts (posyandu and posbindu), curative and traditional medicine by gender-based SAD communities. The combination of four health services that integrated car-based is a model of SAD community empowerment. The Regional Government has to allocate the Budget by providing Bus cars as First Level Health services (FKTP) which make it easier for people to be referred to using BPJS.
\end{abstract}

Keywords: Empowerment, SAD Care, Suku anak Dalam

Korespondensi: Ridwan

Email: fkm.ridwan@unja.ac.id 


\section{PENDAHULUAN}

Provinsi Jambi merupakan daerah yang memiliki populasi Suku Anak Dalam (SAD) cukup banyak. Komunitas adat terpencil ini hidup nomaden di kawasan hutan, terutama dalam kawasan cagar alam atau taman nasional. Komunitas adat terpencil suku anak salam mendiami delapan wilayah daerah tingkat dua, yakni kabupaten Muaro Jambi, Batanghari, Tebo, Sarolangun, Merangin, Bungo, Tanjab Barat, dan Tanjab Timur. Pendataan yang dilakukan didapatkan bahwa jumlah Komunitas Adat Terpencil (KAT) di Provinsi Jambi tahun 2011 sebanyak $6.773 \mathrm{KK}$ atau 28.886 jiwa. sebanyak 3.489 KK atau 14.947 jiwa belum pernah memperoleh pembinaan dan yang pernah memperoleh pembinaan masih belum juga menunjukan hasil sesuai yang diharapkan.

Pemberdayaan mencakup tiga dimensi (1) sebuah proses pembangunan yang di mulai dari pertumbuhan individual, berkembang menjadi sebuah perubahan sosial; (2) sebuah keadaan psikologis yang ditandai oleh rasa percaya diri, rasa berguna dan mampu mengendalikan diri dan orang lain; (3) pembebasan yang dihasilkan dari sebuah gerakan sosial orang-orang lemah dan kemudian melibatkan upaya-upaya kolektif dari orang-orang lemah tersebut untuk memperoleh kekuasaan dan mengubah strukturstruktur yang masih menekan ${ }^{\mathbf{1}}$. Ketidakberhasilan pelaksanaan program pembangunan sosial pemerintah terhadap masyarakat SAD di desa Nyogan disebabkan beberapa faktor penting, diantaranya ketika pemerintah membuat suatu perencanaan pembangunan, masyarakat tidak terlibat. Hal tersebut membuat apa yang menjadi masalah masyarakat tersebut tidak diketahui dengan jelas ${ }^{2}$.

Dari hasil wawancara singkat dengan dinas kesehatan kabupaten Batanghari, diketahui bahwa suku anak di kecamatan batin XXIV memiliki permasalaan spesifik jika kita melihat pola kehidupan dan penghidupan mereka. Permasalahan kesehatan suku anak dalam perilaku hidup bersih dan sehat antara lain kondisi jamban, cuci tangan pakai sabun serta kondisi lingungan pemukiman. Beberapa penyakit yang di hadapi adalah kekurangan gizi, muntaber, malaria dan penyakit gatal-gatal yang sering diderita sebagian masyarakat SAD. Namun, tenaga kesehatan belum mempunyai pola pemberdayaan yang sesuai untuk diterapkan oleh puskesmas pada suku anak dalam tersebut sebagai upaya kemandirian masyarakat suku anak dalam untuk hidup sehat.

\section{METODE}

Penelitian ini menggunakan metode penelitian kualitatif dengan design studi kasus, berlokasi di desa Terap Kecamatan Batin XXIV Kabupaten Batanghari. Informan dalam penelitian ini sebanyak 27 orang yang terdiri 10 orang masyarakat SAD, 1 Orang petugas puskesmas, 1 orang petugas dinas kesehatan dan 4 orang tumenggung/ketua adat. Metode pengambilan sampel menggunakan purposive sampling. Pengumpulan data melalui wawancara mendalam dan FGD pada masyarakat SAD desa terap. Analisis Data menggunakan pendekatan content analysis.

\section{HASIL DAN PEMBAHASAN}

\section{Peningkatan Kapasitas Sad}

Suku anak dalam di desa terap Kecamatan Bathin XXIV masih memerlukan perhatian yang serius, dari hasil observasi di dapatkan bahwa kondisi masyarakat di tinjau dari tempat tinggal mereka bisa dikatakan masih sangat tertinggal, Rumah yang mereka huni beratapkan terpal plastik dan balai-balai terbuat dari kayu-kayu hutan yang ada di sekitarnya. Disamping itu, adat istiadat yang mereka lakukan masih berpegang teguh pada leluhur, yang mereka katakan nenek moyang. Dari hasil penelitian didapatkan bahwa dengan masyarakat KAT yang telah mendapatkan bantuan pemerintah akan lebih cepat mengalami kemajuan dalam tingkat kehidupan masyarakat ${ }^{5}$. Sejalan dengan penelitian lainUntuk menangani pemberdayaan KAT maka harus menjaga sinergitas dengan program kemiskinan dan program pemberdayaan komunitas adat terpencil kementerian sosial dengan pendekatan terintegrasi (integrated approach). dengan program teringraasi di yakini akan dapat mengentaskan kemiskinan dan keterbelakangan komunitas adat terpencil ${ }^{3}$. Untuk pemenuhan 
kebutuhan dasar maka dapat bekerja sama dengan organisasi sosial atau 1SM sesuai dengan bidangnya. Berikut pernyataan responden dari pernyataan responden dikatakan bahwa :

\section{....Kami masih mempertahankan adat} nenek moyang kami...(M7)

Pendapat lainya dikatakan bahwa untuk rumah sebenarnya mereka bisa meminta kepada pemerintah tetapi mereka tetap mempertahankan kehidupannya

...Kalau rumah kita bisa minta ke rajo (Bupati) dibangunkanlah tapi kami masih taat dengan adat nenek moyang kami....(S8)

Untuk itu agar masyarakat dapat meningkatkan kapasitasnya salah satunya adalah masyarakat harus menetap, hal ini tentunya akan mempermudah dalam mengakses fasilitas yang di berikan oleh Negara kepada penduduknya. Salah satu contoh Misalnya KTP yang sangat penting sebagai dasar dalam memberikan program-program pemerintah dalam meningkatkan kesejahteraan salah satunya kesehatan melalui Kartu Indonesia Sehat. Sejalan dengan penelitian bahwa penyelenggaraan model pemberdayaan KAT harus menyediakan tenaga pendamping/pembimbing tehnis lapangan langsung pada KAT, pembimbing harus memiliki komitmen, konsisten, dan kompeten di bidang KAT serta berada lebih intensif dilingkungan KAT sehingga mengenal kehidupan perkembangan yang lebih baik dari hari ke hari ${ }^{4}$. Demikian juga di sungai, keberadaan pendamping merupakan ujung tombak dalam meningkatkan kapasitas masyarakat SAD dalam mengubah perilaku sehat. Oleh karena itu, perlunya pendampingan yang intersif sehingga perubahan-perubahan perilaku tersebut dapat terjadi. Pada saat ini, Kementerian Kesehatan sedang menjalankan program Nusantara sehat sehingga pemerintah daerah dapat merekomendasikan penugasan kelompok dengan tenaga kesehatan yang terdiri dari dokter, bidan, tenaga kesehatan masyarakat , analis, dan apoteker, sangat cocok untuk melakukan pendampingan di Desa Sungai Terap sehingga dalam Kurun waktu satu tahun akan dapat melihat perkembangan yang terjadi.

\section{Ketersediaan Fasilitas pelayanan umum bidang kesehatan (UKBM)}

Hasil Observasi di lapangan di desa terap tempat tingal suku anak, didapatkan bahwa tidak ada fasilitas pelayanan kesehatan tingkat pertama. Tidak ada dokter praktek, tidak ada bidan dan tenaga kesehatan lainya. Hal tersebut menyulitkan bagi suku anak dalam untuk mengakses pelayanan kesehatan. Lokasi masyarakat SAD yang jauh dari pemukiman penduduk dan akses jalan menuju pemukiman yang kurang baik menjadi masalah yang dihadapi dalam mendapatkan akses pelayanan kesehatan. Temuan dalam penelitian ini bahwa pendopo merupakan sarana yang menjadi pusat kegiatan termaksud kegiatan mendapatkan pelayanan kesehatan.

..Untuk kegiatan-kegiatan ,.. di sini lah ami lakukan .. mengumpulkan kelompok kelompok misalnya ado orang kesehatan datang di sini jugo

Kegiatan pelayanan kesehatan yang dilakukan adalah pengobatan masal, dan penyuluhan kesehatan. Secara khusus posyandu atau UKBM lainya belum dibentuk oleh puskemas. Hal ini disebabkan kondisi dan kesiapan tenaga suku anak dalam dalam menjalankan UKBM. Beberapa yang menjadi kendala adalah bahwa pantangan adat istiadat SAD yaitu larangan wanita untuk bertemu dengan pihak laki. Hal tersebut juga tentunya membuat kesulitan dalam berkomunikasi dengan tenaga kesehatan. Dari kegiatan posyandu diantaranya pengukuran berat badan dan imunisasi dilakukan tetapi belum membuat wadah secara nyata dalam mengembangkan UKBM. Dari hasil wawancara dikatakan mereka mau mengikuti pelatihan kader posyandu. Begitu pula dengan posbindu yang dilakukan harus mengikuti dengan kondisi suku anak dalam sehingga hal ini akan dapat membantu mereka dalam meningkatkan upaya preventif dan promotif. 
... Kalau ado yang melatih posyandu kami mau lah....agar anak kami sehat-sehat ...(W3)

Beberapa penyakit yang sering mereka derita adalah gatal-gatal, malaria, dan muntaber beberapa bulan yang lalu ada yang meninggal dan mereka sangat kecewa karena tidak ada tenaga kesehatan yang ada di sekitar tersebut berikut pernyatanya :

....beberapa bulan yang lalu ada keluarga kami yang meninggal tiba-tiba kami dak bisa minta tolong karena orang kesehatan dak ado....(WI)

Beberapa adat istidatat yang mereka miliki adalah ketika keluarga meninggal maka mereka akan berpindah tempat hal ini mereka lakukan agar menghilagkan kesedihan bagi yang keluarga yang di tinggalkannya. Setelah beberapa bulan maka mereka bisa datang kembali ketempat awal setelah mereka merasa dapat melupakan keluarga yang meninggal dunia. Dari permasalahn diatas tentunya perlu melakukan inovasi dalam pelayana kesehatan. Pelayanan kesehatan kepada suku anak dalam dengan kondisi yang jauh dari pemukiman, masyarakat dengan pemukiman yang nomaden tentunya perlu pelayanan kesehatan yang bergerak (mobile). Kendaran di ciptakan untuk mengakses pelayanan kesehatan, upaya promotif dengan posyandu serta dapat menempatkan masyarakat suku anak dalam dengan pengobatan tradisionalnya. perpaduan ke tiga unsur yaitu promotif, kuratif dan pengobatan tradisioanal merupakan upaya yang sangat cocok dilaksanakan di desa terap suku anak dalam. Peralatan yang diperlukan di dalam kendaraan tersebut adalah peralatan posyandu : Timbang balita, kartu KMS, TV penyuluhan, pemeriksaan kehamilan, Bidan KIT, tempat tidur dan alat - alat peraga ( Peraga gosok Gigi ). Posyandu dibangun pada tempat yang mudah di jangkau oleh masyarakat. Kegiatan posyandu terdiri dari pendaftaran, penimbangan, pengisian
KMS penyuluhan kesehatan, pelayanan kesehatan. Untuk pelayanan kesehatan terdiri dari kesehatan ibu dan anak gizi, imunisasi dan $\mathrm{KB}^{\mathbf{5}}$.

Posbindu memiliki kegiatan antara lain pemeriksaan IVA, kolesterol, pemeriksaan gula darah, kegiatan pengukuran IMT, dan penyuluhan Kesehatan. Posbindu dapat meningkatkan kemampuan masyarakat misalnya, Diet, aktifitas Fisik, stress. Dan untuk perilaku merokok ${ }^{5}$. Semua alat-alat ini di siapkan dalam mobil pelayanan Suku anak dalam. Mobil yang melakukan pelayanan ini sekaligus dapat menjadi FKTP sehingga setelah mendapat rujukan dari pelayana khusus ini masyarakat suku anak dalam dapat melanjutkan pelayanan ke tingkat berikutnya. hal ini untuk memudahkan masyarakat suku anak dalam untuk mengakses pelayanan kesehatan mobil yang di disain ini di namakan dengan "SAD Care". Kendaraan ini dapat bergerak sesuai dengan kebutuhan mengingat masyarakat suku anak dalam yang menyebar dan sulit di jangkau namun mereka butuh pelayanan kesehatan. Dari hasil penelitian di katakan bahwa masyarakat KAT mengalami peningkatan lebih layak dengan bantuan pemukiman dan kesehatan dari pemerintah daerah ${ }^{6}$. untuk itu pemerintah daerah agar membantu masyarakat SAD sungai terap untuk meningkatkan pelayanan kesehatan dan kesejahteraan ekonomi. Penelitian lain menunjukan bahwa untuk memberdayakan komunitas adat terpencil diperlukan kebijakan yang akurat, penanganan yang memadai dan pelayanan yang dapat mengentaskan mereka dari masalahnya ${ }^{3}$. Selain itu di perlukan kebijakan alternative untuk penyelesaian masalahnya. Perlunya pengembangan KIE, Simulasi, dan dialog dalam upaya promosi Perilaku Hidup Bersih dan Sehat (PHBS) khususnya terkait kepercayaan kesehatan pada masyarakat suku Taburta perlu melibatkan peran serta para tokoh adat/kepala suku sebagai penutur asli nilai dan noma masyarakat. Suku Taburta Pada dasarnya masyarakat suku anak dalam mempunyai cara pengobatan sendiri. 
Tabel 1. Kebutuhan peralatan yang dalam pelayanan kesehatan SAD

\begin{tabular}{|c|c|c|c|}
\hline No & Pelayanan & Kebutuhan & SDM \\
\hline 1 & Posyandu & $\begin{array}{l}\text { Timbangan, KMS, tempat tidur, Bidan } \\
\text { KIT, alat peraga kebersihan diri ( sikat } \\
\text { gigi, buah, buahan, cuci tangan) }\end{array}$ & $\begin{array}{l}\text { Kader, tenaga kesehatan (Bidan, } \\
\text { kesehatan masyarakat) }\end{array}$ \\
\hline 2 & Posbindu & $\begin{array}{l}\text { Pemeriksaan kolestreol, cek gula darah, } \\
\text { IMT, tensimeter, kaset senam }\end{array}$ & $\begin{array}{l}\text { Kader, tenaga kesehatan (Bidan, } \\
\text { kesehatan masyarakat) }\end{array}$ \\
\hline 3 & $\begin{array}{l}\text { Kendaraan Roda } \\
\text { Empat (BUS) }\end{array}$ & $\begin{array}{l}\text { Peralatan medis, obat-obatan, tabung } \\
\text { oksigen, tempat tidur pasien, Screen } \\
\text { Televisi, DVD, sound system }\end{array}$ & Sopir \\
\hline 4 & $\begin{array}{l}\text { Pengobatan } \\
\text { tradisional }\end{array}$ & Tempat tidur, obat racikan & $\begin{array}{l}\text { Masyarakat suku anak dalam (SAD) } \\
\text { yang memilki kemampuan, Dukun } \\
\text { beranak yang di gunakan untuk } \\
\text { memotivasi bagi ibu yang kan bersalin } \\
\text { membantu bidan }\end{array}$ \\
\hline
\end{tabular}

Misalnya obat demam, batuk, sakit Gigi, Luka bakar ${ }^{7}$. Selain itu masyarakat suku anak dalam dapat mengobati dengan mantra-mantra yang di bacakan. Menjadi masalah ketika masyarkat $\mathrm{SAD}$ menggunakan pengobatan tradisional adalah mereka kesulitan dala mencari bahan baku mengingat hutan yang tidak banyak lagi. Nilai-nilai cultural adalah penting dalam pengembangan masyarakakat untuk seorang pekerja sosial, ia harus mengerti dan menerima dan bila mungkin untuk mengesahkan kultur tersebut untuk di gunakan sebagai titik permulaan untuk bekerja menuju perubahan ${ }^{8}$.

Dari observasi dilapangan di dapatkatkan bahwa untuk pelayana kesehatan promotif , preventif di manfaatkan pendopo yang tersedia di desa terap. Masyarakat SAD hanya mendapatkan pelayanan kesehatan ketika dilakukan pengobatan masal, yang dilakukan Puskesmas. Upaya kesehatan bersumber daya masyarakat misalnya Posyandu belum dilakukan. Kegatan pemantau balita hanya dilakukan ketika pengobatan masala sehingga pertumbuhan dan perkembangan balita tidak bisa dilakukan secara Rutin dalam upaya mencegah masalah-masalah kesehatan oleh masyarakat SAD Desa Terap. Keberadaan posyandu, Posbindu dan lainya merupakan hal terpenting dalam meningkatkan kesadaran masyarakat suku anak dalam. Dengan adanya posyandu maka masyarakat akan di berikan edukasi tentang kesehatan, gizi, dan kebersihan diri terutama kesehaan anak-anak. Hal yang perlu dilakukan adalah dengan membuat mobil khusus yang di dalammnya terdapat peralatan posyandu, pencatatan dan edukasi bagi suku anak dalam. Yang secara rutin. Tentunya di dalam mobil terdapat tempat pemeriksaan kesehatan bagi SAD yang dilengkapi Bidan Kit, yang di guankan bila ada yang bersalin. Bila di lihat penyakit yang di miliki oleh masyarakat SAD adalah masalah Gizi, muntaber, malaria, gatal-gatal hal ini merupakan penyebab kurangnya kebersihan diri masyarakat.

\section{Kesiapan SDM kesehatan dalam pemberdayaan}

Tenaga Kesehatan dalam mendukung kegiatan Suku anak dalam di kelompok sungaiterap masih belum maksimal, dari hasil observasi dilapangan bahwa tenaga kesehatan hadir dengan waktu yang tidak di tentukan melalui pengobatan masal. Dari wawancara mendalam dengan Tumenggung mengatakan mereka mengharapkan bahwa tenaga kesehatan harus siap di lokasi jika suatu saat di perlukan. Dari pernyataan responden beberapa minggu kemaren ada anggota masyarakat yang terkena penyakit pada akhirnya meninggal karena terlambatnya mendapat pengobatan, hal ini dinyatakan oleh responden $\mathrm{T} 1$

...Kami berharap tenaga kesehatan siap di tempat kami, kalau ado masyarakat perlu bisa panggil secepatnyo... (T1) 
Menjadi suatu kebutuhan bagi masyarakat Suku anak dalam dalam pelayanan kesehatan untuk pengobatan sendiri masih mereka lakukan misalnya pertolongan persalinan meraka masih bisa lakukan dengan dukun beranak yang mereka milki. Saat ini masyarakat SAD semakin yakin dengan pengobatan oleh medis hal ini dinyatakan oleh responden mereka bila sakit maka dia berobat ke sarolangun atau kebatanghari kadang mereka di rujuk ke Jambi. Dari hasil wawancara untuk pergi ke jambi berobat yang paling sulit adalah biaya untuk menunggu keluarga, makan dan keperluan sehari-hari. Sebuah Tradisi yang selaras dengan pengetahuan masa kini, akan sangat efektif dalam upaya untuk meningkatkan motivasi tenaga kesehatan dalam bekerja ${ }^{9}$. Hal ini didukung hasil penelitian yang dilakukan di Amerika Serikat, Polandia, dan HongKong yang melaporkan bahwa perilaku kepatuhan dipengaruhi oleh budaya atau tradisi ${ }^{10}$. Hasil Penelitian lain di Kenya menyatakan bahwa motivasi tenaga kesehatan dapat dipengaruhi oleh hal-hal yang bersifat kontekstual dari budaya setempat ${ }^{\mathbf{1 1}}$.

Dari hasil diskusi terarah warga SAD di sungai terap mau jika ada pelatihan -pelatihan kesehatan salah satunya bila dilatih menjadi kader. Kader posyandu berjumlah 5 orang. Untuk menjalankan posyandu maka kader harus mengikuti tahapan pelatihan terlebih dahulu ${ }^{\mathbf{1 2}}$. Kader posbindu berjumlah 7 orang yang harus dilakukan sebelum melakukan kegiatan posbindu PTM ${ }^{\mathbf{1 3}}$.

Dalam mengoperasikan SAD care maka fungsi dari masing tenaga menjadi sangata penting sehingga pemberdayaan terhadap suku anak dalam akan dapat dilakakan secara berkelanjutan berikut peran masing-msing tenaga yang akan melakukan pemberdayaan di suku anak dalam di desa Terap.

Tabel 2. Kebutuhan dan peran tenaga yang dibutuhkan dalam pelayanan $\mathrm{SAD}$

\begin{tabular}{|c|c|c|}
\hline No & $\begin{array}{l}\text { Tenaga yang } \\
\text { dibutuhkan }\end{array}$ & Peran \\
\hline 1 & $\begin{array}{l}\text { Kesehatan } \\
\text { masyarakat } 1 \\
\text { orang }\end{array}$ & $\begin{array}{l}\text { Melakukan pelatihan-pelatihan } \\
\text { kader, penggerakan masyarakat } \\
\text { SAD, edukasi bagi masyarakat } \\
\text { dan kader }\end{array}$ \\
\hline 2 & Bidan 1 orang & $\begin{array}{l}\text { Pelayanan kesehatan Dasar, } \\
\text { pertolongan persalinan }\end{array}$ \\
\hline 3 & $\begin{array}{l}\text { Kader posbindu } \\
7 \text { orang }\end{array}$ & $\begin{array}{l}\text { Mengajak masyarakat, } \\
\text { menggerak masyarakat, dan } \\
\text { melatih masyarakat, } \\
\text { mengumpulkan masyarakat }\end{array}$ \\
\hline 4 & $\begin{array}{l}\text { Kader } \\
\text { Posyandu } 5 \\
\text { orang }\end{array}$ & $\begin{array}{l}\text { Mengajak masyarakat, } \\
\text { menggerak masyarakat, dan } \\
\text { melatih masyarakat, } \\
\text { mengumpulkan masyarakat }\end{array}$ \\
\hline
\end{tabular}

\section{KESIMPULAN DAN SARAN}

Sebagian besar masyarakat Suku anak dalam di Desa Terap masih perlu ditingkatkan kemampuan dalam menjaga kebersihan diri, kebersihan lingkungan pemukiman, gizi dan tumbuh kembang anak. Masyarakat SAD desa terap memiliki kebiasaan berpindah - pindah pemukiman. Mereka hidup berkelompokkelompok. akses jalan sangat sulit untuk mencapai lokasi pemukiman. Dengan Kondisi tersebut maka upaya pemberdayaan bidang Kesehatan adalah memadukan konsep promotif dan preventif, Kuratif serta pengobatan tradisonal dengan menggunakan mobil khusus yang didalamnya berisi peralatan Posyandu, posbindu, pengobatan medis dan pengobatan tradsional Suku anak dalam dengan menamakan mobil "SAD care " yang bisa digunakan sebagai fasilitas pelayanan Tingkat Pertama (FKTP). Pemerintah Daerah agar mengalokasikan Anggaran dengan menyediakan mobil Bus sebagai pelayanan Kesehatan Tingkat Pertama (FKTP) yang memudahkan masyarakat jika harus dirujuk menggunakan kartu BPJS.

\section{DAFTAR PUSTAKA:}


1. Parsons, R. J., Jorgensen, J.D.Z., Hernandez, H.S. (1994). The Integration Of Social Work Practice. California : Wadsworth, Inc.

2. Mahmud \& Kusnadi , 2010. Pembangunan Social masyarakat terasing di era Media Akademika Volume 25, No. 4, Oktober 2010

3. Notoadmodjo, 2010, Ilmu perilaku Kesehatan, Rineka Cipta Jakarta

4. Ariningrum \& Sukoco. Studi Kualitatif pelayanan Kesehatan untuk kelompo adat terpencil (KAT) dikabupaten kepulauan Mentawai, Buletin penelitian KesehatanVol 15 n0.3 Juli 2012:250-258

5. Kemensos RI. 2009. Petunjuk Teknis: Pelaksanaan Pemberdayaan Komunitas Adat Terpencil melalui Dekonsentrasi Jakarta

6. Ferika (2015) Pelaksnaan Program pemberdayaaan Komunitas adat terpencil oleh dias Sosial selat Baru kecamatan bantan kabupaten Bengkalis tahun 20102014, Jom FISIP N0.2 vol 2 Oktober 2015

7. Sagrim, noor Nasry, M.Thaha \& Maidin 2015 Kearifan lokal Komunitas adat terpencil suku Taburta dalam Perilaku Hidup Bersih dan sehat berbasis Rumah tangga. Jurnal MKMI Desember 2012, hal 218-227
8. Ife \& Tesoriero, 2006 Community Development : Communnity -based Alternative, pearson education Australia

9. Canbulat, N., \& Uzun, O. 2008. Health beliefs and breast cancer screening behaviors among female health workers in Turkey. European Journal of Oncology Nursing : The Official Journal of European Oncology Nursing Society, 12, 148-156. Available at: $\quad$ http://doi. org/10.1016/j.ejon.2007.12.002

10. Chen, S. X., Hui, N. H. H., Bond, M. H., Sit, A. Y. F., Wong, S., Chow, V. S. Y., ... Law, R. W. M. 2006. Reexamining personal, social, and cultural infl uences on compliance behavior in the United States, Poland, and Hong Kong. The Journal of Social Psychology, 146, 223-244. Available at: http://doi.org/10.3200/ SOCP.146.2.223-244

11. Mbindyo, P., Gilson, L., Blaauw, D., \& English, M. 2009. Contextual infl uences on health worker motivation in district hospitals in Kenya. Implementation Science : IS, 4, 43. available at: http://doi.org/10.1186/1748- 5908-4-43.

12. Kemenkes RI 2011, pedoman uтиm pengelolaaan Posyandu, Jakarta

13. Kemenkes RI 2012, pedoman uтит penyelangaraan pos Pembinaan Terpadu Penyakit tidak menular (POSBINDU PTM) Jakarta. 